09.1

\title{
Исследование спектров комплексного показателя преломления пленок мононуклеотидов на кремнии в терагерцевом диапазоне
}

\author{
() А.С. Кулагина ${ }^{1}$, В.Н. Трухин ${ }^{2}$, Д.Д. Ступин ${ }^{3}$, А.Л. Чернев ${ }^{4}$, М.В. Дубина ${ }^{5}$, Г.Э. Цырлин ${ }^{1-3,6}$ \\ ${ }^{1}$ Санкт-Петербургский государственный университет, Санкт-Петербург, Россия \\ ${ }^{2}$ Физико-технический институт им. А.Ф. Иоффее РАН, Санкт-Петербург, Россия \\ ${ }^{3}$ Санкт-Петербургский национальный исследовательский Академический университет им. Ж.И. Алфёрова РАН, \\ Санкт-Петербург, Россия \\ ${ }^{4}$ Swiss Federal Institute of Technology Lausanne (EPFL), Lausanne, Switzerland \\ ${ }^{5}$ Государственный научно-исследовательский институт особо чистых биопрепаратов ФМБА России, Санкт-Петербург, \\ Россия \\ ${ }^{6}$ Институт аналитического приборостроения РАН, Санкт-Петербург, Россия \\ E-mail: a.s.panfutova@gmail.com
}

Поступило в Редакцию 10 марта 2021 г.

В окончательной редакции 14 мая 2021 r.

Принято к публикации 26 мая 2021 г.

\begin{abstract}
Впервые показана возможность получения спектров комплексного показателя преломления мононуклеотидов, осажденных в виде пленок на полированную кремниевую пластину, в терагерцевом (THz) диапазоне. C помощью $\mathrm{THz}$-спектрометра измерено пропускание образцов биополимеров. Определены собственные частоты поглощения и спектр показателя преломления аденозина в терагерцовом диапазоне.
\end{abstract}

Ключевые слова: ДНК, терагерцевая спектроскопия, безметочный метод регистрации собственных частот поглощения олигонуклеотидов, технологии на кремнии.

DOI: 10.21883/PJTF.2021.17.51383.18757

Частотную дисперсию оптических параметров ДНК сегодня исследуют, применяя комбинационное рассеяние света, инфракрасную Фурье-спектроскопию, терагерцевую времяразрешенную спектроскопию. Собственные частоты поглощения олигонуклеотидов лежат в THz-диапазоне [1]. В [1] показано, что из таких спектров может быть получена информация о вторичной и третичной структуре олигонуклеотидов. Недостатками современных методов секвенирования являются накопление ошибок при использовании дополнительного звена в виде флуоресцентного красителя, неточность сбора данных при исследовании гомополимерных олигонуклеотидных молекул, некорректный анализ образцов с олигонуклеотидными полиморфизмами [2]. В настоящей работе впервые реализован простой метод прямого нанесения олигонуклеотидов из исходных растворов на кремниевую подложку для последующего получения спектров собственных частот поглощения мононуклеотидов без использования модификаторов, флуоресцентных меток и красителей в режиме реального времени при комнатной температуре.

Объектом исследований являлись мононуклеотиды (dATP - аденозинтрифосфат, dTTP - тимидинтрифосфат, dGTP - гуанозинтрифосфат, dCTP - цитидинтрифосфат), синтезированные в ООО „ДНК-Синтез“ (Москва). В качестве подложек использовались нелегированные полированные с обеих сторон кремниевые пластины (100) толщиной $350 \mu \mathrm{m}$. Подложки были подготовлены по стандартной процедуре с использованием изопропилового спирта, дистиллированной деионизиро- ванной воды и ацетона. В процессе пробоподготовки было замечено, что однородность осажденной капельным способом пленки напрямую зависит от концентрации мононуклеотидов и температуры подложки (рис. 1). На рис. 1, $a$ представлен результат осаждения мононуклеотидов на подложку, охлажденную до температуры $-80^{\circ} \mathrm{C}$, которая обычно используется в технологии выделения ДНК в режиме шоковой заморозки [3]. Однако лучшего смачивания каплей подложки удалось добиться, когда температура подложки равнялась комнатной (рис. $1, b)$. Отметим, что ранее при комнатной температуре были исследованы образцы ДНК-оснований, спрессованных в таблетку с порошком полиэтилена толщиной 200-400 $\mu \mathrm{m}$ [4]. В наших исследованиях наиболее однородный слой мононуклеотидов на кремнии был получен при следующих условиях: раствор dATP в деионизированной воде, имеющий концентрацию $0.05 \mathrm{M}$, в объеме $50 \mu 1$ осаждался на кремниевую пластину при комнатной температуре, а затем высушивался в лиофильной камере Alfa 1-2 LDplus (Martin Christ Gefriertrocknungsanlagen $\mathrm{GmbH}$, Германия) на протяжении 4-5 h (рис.1, $b$, ряд 2).

Оптические измерения пленки, изображенной на рис. $1, b$ в ряду 2 , проводились с помощью THz-спектрометра (рабочий диапазон $0.1-3 \mathrm{THz}$ ), подробное описание которого представлено в работе [5]. Регистрировались волновые формы THz-импульсов, прошедших через чистую кремниевую подложку и через нее же, но с осажденными олигонуклеотидами. Ввиду того что образцы (пленки мононуклеотидов) имели малую толщину (около $20 \mu \mathrm{m}$ ), для снижения погрешности для 

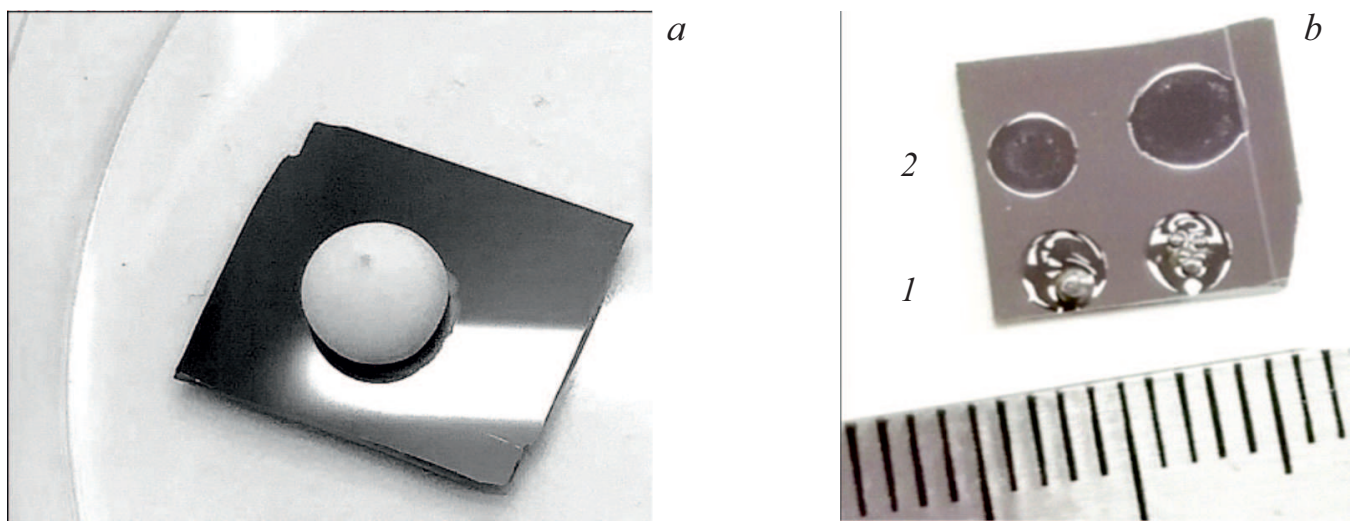

Рис. 1. Фотографии мононуклеотидов dATP, осажденных на кремниевую пластину. $a-$ пластина охлаждена до $-80^{\circ} \mathrm{C}$; $b$ - при комнатной температуре: в ряду 1 концентрация составляет $0.5 \mathrm{M}$, в ряду $2-0.05 \mathrm{M}$; шаг линейки $1 \mathrm{~mm}$.

$a$
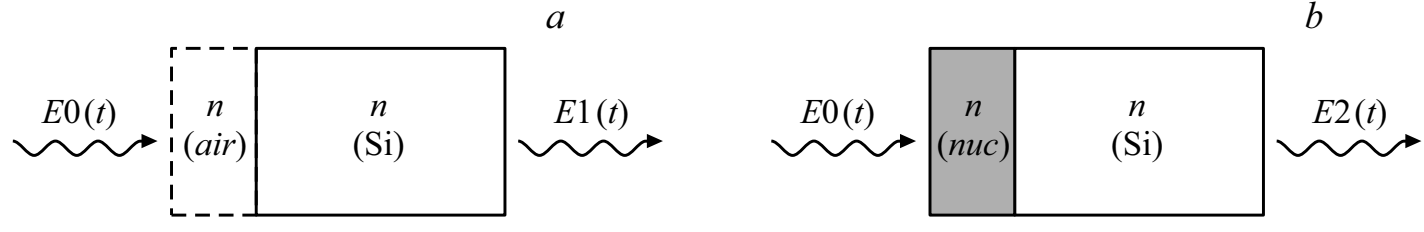

Рис. 2. Схема распространения ТНz-излучения через образцы. $E_{0}(t)-$ поле входной волны, $E_{1}(t), E_{2}(t)-$ поля волны, прошедшей через слой воздуха и нуклеотидов соответственно.
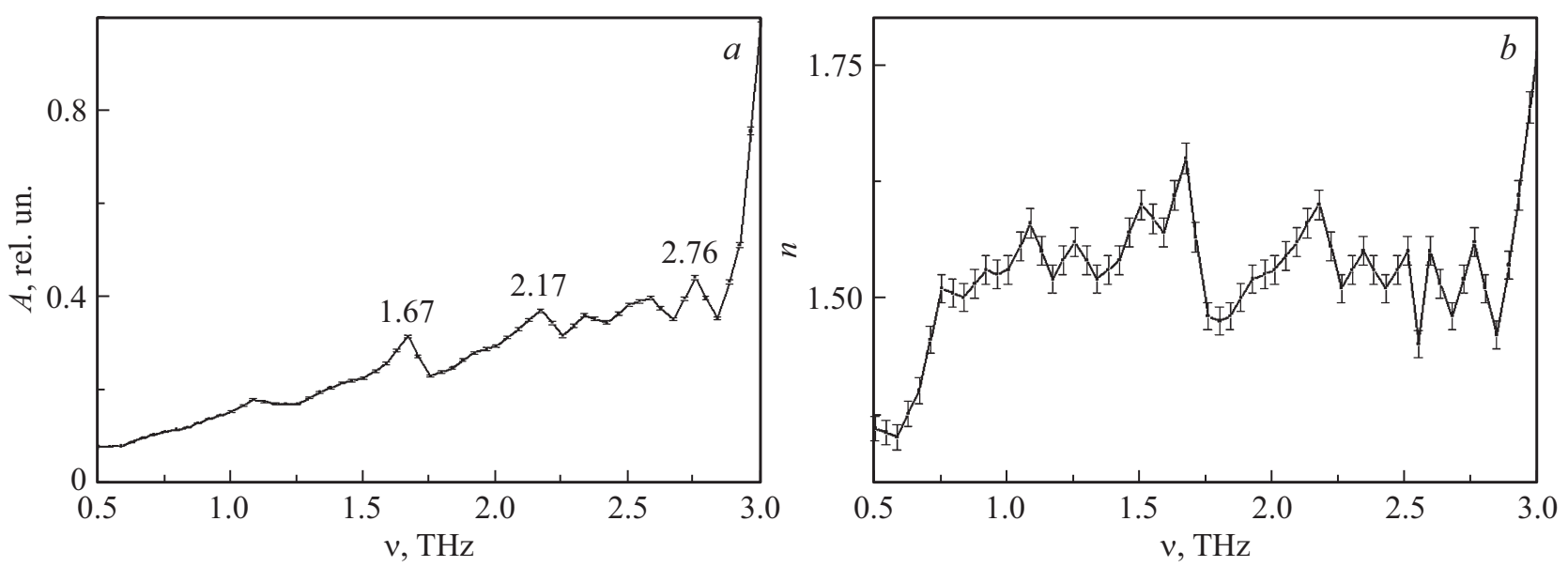

Рис. 3. Нормированный спектр поглощения $(a)$ и дисперсия показателя преломления $(b)$ мононуклеотидов dATP на кремнии. Вертикальными отрезками показана величина погрешности.

каждого типа нуклеотидов использовалась своя подложка. Частотные характеристики спектров показателя преломления и поглощения определялись с помощью преобразования Фурье волновой формы нормированного дифференциального сигнала. Комплексный показатель преломления пленки нуклеотидов рассчитывался по известной из эксперимента зависимости амплитуды THz-импульса, прошедшего через образцы чистой подложки $\mathrm{Si}$ (рис. 2,a) и подложки с осажденными нуклеотидами (рис. 2,b).

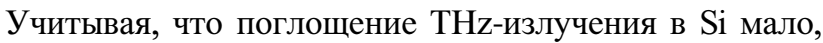
а толщина биополимера мала по сравнению с длиной волны, выражение для изменения пропускания за счет слоя нуклеотидов можно записать в виде [6]:

$$
\frac{E_{2}(\omega)-E_{1}(\omega)}{E_{1}(\omega)}=T(\omega)=i \frac{\omega d}{c\left(n_{\mathrm{Si}}+1\right)}\left(\hat{n}_{n u c}^{2}-1\right) .
$$

Здесь $\omega$ - круговая частота падающего излучения, $d$ - толщина слоя нуклеотидов, $E_{2}(\omega)$ и $E_{1}(\omega)-$ Фурье-образы THz-импульсов $E_{2}(t)$ и $E_{1}(t), c-$ скорость света, $n_{\mathrm{Si}}$ - показатель преломления кремниевой пластины, $n_{n u c}$ - показатель преломления нуклеотидов $\left(\hat{n}_{n u c}^{2}=\varepsilon_{n u c}^{\prime}+i \varepsilon_{n u c}^{\prime \prime}\right.$, где $\varepsilon_{n u c}^{\prime}$ и $\varepsilon_{n u c}^{\prime \prime}-$ действительная и мнимая части диэлектрической проницаемости для 
случая нормального падения). По определению относительную дифференциальную величину пропускания $T(\omega)$ можно представить в виде $T(\omega)=\rho(\omega) e^{i \Delta(\omega)}$, где $\rho$ и $\Delta$ - амплитуда и фаза Фурье-спектра дифференциального нормированного сигнала. Соответственно коэффициент поглощения и показатель преломления мононуклеотидов можно выразить через действительную и мнимую части диэлектрической проницаемости [7], которые определяются, согласно (1), как

$$
\begin{gathered}
\varepsilon_{\text {nuc }}^{\prime}=1+\frac{c}{\omega d}\left(n_{\mathrm{Si}}+1\right) \rho \sin \Delta, \\
\varepsilon_{n u c}^{\prime \prime}=-\frac{c}{\omega d}\left(n_{\mathrm{Si}}+1\right) \rho \cos \Delta .
\end{gathered}
$$

В исследуемом диапазоне частот показатель преломления $\mathrm{Si}$ оставался постоянным и равным по величине 3.42 [8]. С помощью выражений (1) и (2) исходя из экспериментальных результатов нами были определены собственные частоты поглощения и спектр показателя преломления пленки dATP на кремнии (рис. 3).

Как видно из сравнения со спектрами dATP, полученными в работе [4], основные полосы поглощения, а также величина показателя преломления в пределах разрешения эксперимента совпадают. Аналогичные спектры были получены для пленок dTTP, dGTP, dCTP и показали хорошее совпадение с литературными данными.

Практическая ценность работы заключается в расширении способов характеризации олигонуклеотидов в THz-диапазоне частот без использования модификаторов, флуоресцентных меток и красителей в режиме реального времени при комнатной температуре.

\section{Финансирование работы}

Экспериментальные исследования проведены при поддержке субсидии Комитета по науке и высшей школе Санкт-Петербурга молодым ученым 2019 г. Содержательная часть работы выполнена при поддержке гранта Российского научного фонда № 21-72-30020.

\section{Конфликт интересов}

Авторы заявляют, что у них нет конфликта интересов.

\section{Список литературы}

[1] D.L. Woolard, W.R. Loerop, M.S. Shur, Terahertz sensing technology volume: emerging scientific applications and novel device concepts (World Scientific, Singapore, 2004), vol. 2.

[2] E.R. Mardis, Ann. Rev. Anal. Chem., 6 (1), 287 (2013). DOI: 10.1146/annurev-anchem-062012-092628

[3] S. Viale-Bouroncle, M. Gosau, C. Morsczeck, Arch. Oral Biology, 59 (12), 1249 (2014).

DOI: 10.1016/j.archoralbio.2014.07.013

[4] B.M. Fischer, M. Walther, P.U. Jepsen, Phys. Med. Biol., 47 (21), 3807 (2002). DOI: 10.1088/0031-9155/47/21/319
[5] В.Н. Трухин, А.Д. Буравлёв, И.А. Мустафин, Г.Э. Цырлин, Д.И. Курицын, В.В. Румянцев, С.В. Морозов, J.P. Kakko, Т. Huhtio, Н. Lipsanen, ФТП, 50 (12), 1561 (2016). DOI: $10.1134 / \mathrm{S} 1063782616120241$

[6] A.V. Andrianov, A.N. Aleshin, V.N. Trukhin, A.V. Bobylev, J. Phys. D: Appl. Phys., 44 (26), 265101 (2011). DOI: $10.1088 / 0022-3727 / 44 / 26 / 265101$

[7] М. Борн, Э. Вольф, Основы оптики (Наука, М., 1973).

[8] J. Dai, J. Zhang, W. Zhang, D. Grishkovskii, J. Opt. Soc. Am. B, 21 (7), 1379 (2004). DOI: 10.1364/JOSAB.21.001379 